\title{
Cognitive Heterogeneity across Schizophrenia and Bipolar Disorder: A Cluster Analysis of Intellectual Trajectories
}

\author{
Anja Vaskinn ${ }^{1,2, *}$ (D) , Beathe Haatveit ${ }^{1}$, Ingrid Melle ${ }^{1,2}$, Ole A. Andreassen ${ }^{1,2}$, Torill Ueland ${ }^{1,3}$ and Kjetil Sundet $^{1,3}$ \\ ${ }^{1}$ Norwegian Centre for Mental Disorders Research, Oslo University Hospital, Oslo, Norway \\ ${ }^{2}$ Institute of Clinical Medicine, University of Oslo, Oslo, Norway \\ ${ }^{3}$ Department of Psychology, University of Oslo, Oslo, Norway
}

(Received November 21, 2019; Final Revision February 10, 2020; Accepted March 13, 2020; First Published Online May 19, 2020)

\begin{abstract}
Objective: Cognitive dysfunction cut across diagnostic categories and is present in both schizophrenia and bipolar disorder, although with considerable heterogeneity in both disorders. This study examined if distinct cognitive subgroups could be identified across schizophrenia and bipolar disorder based on the intellectual trajectory from the premorbid phase to after illness onset. Method: Three hundred and ninety-eight individuals with schizophrenia $(n=223)$ or bipolar I disorder $(n=175)$ underwent clinical and neuropsychological assessment. Hierarchical and $k$-means cluster analyses using premorbid (National Adult Reading Test) and current IQ (Wechsler Abbreviated Scale of Intelligence) estimates were performed for each diagnostic category, and the whole sample collapsed. Resulting clusters were compared on neuropsychological, functional, and clinical variables. Healthy controls $(n=476)$ were included for analyses of neuropsychological performance. Results: Cluster analyses consistently yielded three clusters: a relatively intact group (36\% of whole sample), an intermediate group with mild cognitive impairment (44\%), and an impaired group with global deficits $(20 \%)$. The clusters were validated by multinomial logistic regression and differed significantly for neuropsychological, functional, and clinical measures. The relatively intact group (32\% of the schizophrenia sample and $42 \%$ of the bipolar sample) performed below healthy controls for speeded neuropsychological tests. Conclusions: Three cognitive clusters were identified across schizophrenia and bipolar disorder using premorbid and current IQ estimates. Groups differed for clinical, functional, and neuropsychological variables, implying their meaningfulness. One-third of the schizophrenia sample belonged to the relatively intact group, highlighting that neuropsychological assessment is needed for the precise characterization of the individual.
\end{abstract}

Keywords: Schizophrenia, Bipolar disorder, Cognition, Heterogeneity, Neuropsychology, Psychosis

\section{INTRODUCTION}

Although not a diagnostic criterion, cognition has been at the core of a large body of research that over the last quarter of a century has increased our understanding of severe mental disorder substantially. In addition to studies that have established that individuals with schizophrenia (Kahn \& Keefe, 2013) and bipolar disorder (Arts, Jabben, Krabbendam, \& van Os, 2008; Bora, Yucel, \& Pantelis, 2009) experience cognitive impairments (Bortolato, Miskowiak, Köhler, Vieta, \& Carvalho, 2015), research has shown that variation in cognition is an important determinant of functional outcome in schizophrenia (Green, Kern, \& Heaton, 2004) as well as

*Correspondence and reprint requests to: Anja Vaskinn, Oslo University Hospital, Division Mental Health and Addiction, Psychosis Research Unit/ TOP, PO Box 4956 Nydalen, 0424 Oslo, Norway. E-mail: anja.vaskinn@ medisin.uio.no bipolar disorder (Baune \& Malhi, 2015). This has paved the way for new treatment interventions with cognition as the primary target (Wykes, Huddy, Cellard, McGurk, \& Czobor, 2011).

While cognitive impairments are central to severe mental illness, there is substantial cognitive heterogeneity in both schizophrenia and bipolar disorder. A recent review of the literature on schizophrenia spectrum disorders (Carruthers, Van Rheenen, Gurvich, Sumner, \& Rossell, 2019a) concluded that most commonly three distinct cognitive subgroups emerge, regardless of the methodology used to tease out the heterogeneity. The subgroups that emerge are a relatively intact group with high cognitive performance, an intermediate group with mild-moderate cognitive impairment, and a globally impaired subgroup characterized by substantial cognitive impairment (Carruthers et al., 2019a). Different approaches have been taken to arrive at these 
cognitive subgroups. Whereas some studies have applied clinical classification criteria, others have used data-driven approaches. Further, some research has been based on current neuropsychological test performance, while cognitive trajectories have been examined in other studies.

One specific line of studies has focused on intellectual trajectories from the premorbid phase to after illness onset in examinations of cognitive heterogeneity in schizophrenia. Clinical classification methods have used premorbid and current IQ scores to arrive at three cognitive subgroups. The preserved group is defined by a premorbid IQ score $>90$ and $<10$ points of decline from premorbid to current IQ, the deteriorated group has $\geq 10$ IQ points decline, and the compromised group has a premorbid IQ $<90$ (and a IQ decline $<10$ points) (Weickert et al., 2000). Studies using this clinical classification method have confirmed the groups using empirical clustering methods (Weickert et al., 2000; Wells et al., 2015). The subgroups have been shown to differ in cognitive profile (Weickert et al., 2000; Wells et al., 2015), functional outcome (Wells et al., 2015), symptom profile (Wells et al., 2015), and brain volume or cortical thickness (Weinberg et al., 2016; Van Rheenen et al., 2018). Specifically, the compromised subgroup has been reported to have impairments in some cognitive domains that are not impaired in the other subgroups, that is, language and visual processing (Weickert et al., 2000) and visuospatial abilities (Wells et al., 2015). Further, although brain volume and thickness reductions are present in all cognitive subgroups compared to healthy controls, the compromised subgroup seems to show additional abnormalities in some brain regions (Van Rheenen et al., 2018). They also have lower global functioning scores (Wells et al., 2015). Although these studies can provide indications of cognitive development, they are cross sectional in nature and therefore present putative development.

In the case of bipolar disorder, data-driven cluster analytic studies have also identified three discrete cognitive subgroups (Burdick et al., 2014; Jensen, Knorr, Vinberg, Kessing, \& Miskowiak, 2016; Van Rheenen et al., 2017); severely impaired, mildly impaired, and relatively intact that also extend to schizophrenia in cross-diagnostic studies (Van Rheenen et al., 2017). In some studies, a fourth moderately impaired group appears, with neuropsychological performance which is intermediate to the severely and mildly impaired subgroups (Lewandowski, Sperry, Cohen \& Öngur, 2014; Lewandowski, Baker, McCarthy, Norris, \& Öngur, 2018). Generally, in cross-diagnostic research, the relatively intact group performs in line with healthy controls (Van Rheenen et al., 2017) or normative data (Lewandowski et al., 2014) on neuropsychological tests, sometimes with slightly worse performance in some domains (Van Rheenen et al., 2017) and slightly better performance in other domains (Lewandowski et al., 2014; Van Rheenen et al., 2017). The intermediate cognitive subgroups show significant impairments in all domains, roughly within 1-1.5 standard deviations of healthy controls (Van Rheenen et al., 2017; Lewandowski et al., 2018). The severely impaired group has substantial impairments present in all domains (Lewandowski et al., 2014; Van Rheenen et al., 2017; Lewandowski et al., 2018). These cross-diagnostic cognitive subgroups have been shown to differ in a step-wise manner with regard to functioning, with the severely impaired subgroup evidencing the most pronounced deficits in community functioning (Lewandowski et al., 2018).

The substantial heterogeneity of schizophrenia and bipolar disorder tampers our efforts to provide adequate treatment. One step toward providing better and optimized treatment is to increase our understanding of cognitive heterogeneity. The question of whether identified cognitive subgroups are meaningful and important can only be answered through their external validation, that is, by showing that they are neurobiologically different and have different psychosocial outcomes or treatment responses (Carruthers et al., 2019a). In order to embark on that journey, we need studies that examine the cognitive heterogeneity from a variety of angles, providing evidence to either support or question the existence of cognitive subgroups.

For instance, it is unclear if using the intellectual trajectory as a means to understand cognitive heterogeneity will produce the same cognitive subgroups for bipolar disorder as has been shown for schizophrenia. Whereas schizophrenia is considered a neurodevelopmental disorder, with early, premorbid cognitive impairment, further decline around disease onset, and a static course after illness onset, the picture is less clear for bipolar disorder (Sheffield, Karcher \& Barch, 2018). In fact, important differences between schizophrenia and bipolar disorder have been reported in that both high childhood IQ (Koenen et al., 2009; Smith et al., 2015) and excellent school performance in adolescence (MacCabe et al., 2010) as well as low premorbid IQ (Tiihonen et al., 2005) may confer risk for bipolar disorder. This is in contrast to schizophrenia (Bora, 2015) for which low childhood (Khandaker, Barnett, White, \& Jones, 2011) or low adolescent (Kendler, Ohlsson, Sundquist, \& Sundquist, 2015) IQ is considered a risk factor. Cognitive impairments thus appear to provide a linear risk for schizophrenia, but a U-shaped risk for bipolar disorder, with above-average cognitive functioning increasing the risk more than low IQ (Parellada, GomezVallejo, Burdeus, \& Arango, 2017). This clearly implies the existence of different cognitive subgroups within the diagnostic category of bipolar disorder. Inconsistent results concerning cognitive course after illness onset may be explained by cognitive heterogeneity. Although one review concluded that bipolar disorder (affective psychosis) seems to be characterized by cognitive deficits that worsen over time after illness onset, suggesting neuroprogressive processes (Sheffield et al., 2018), other studies indicate stability of cognitive functioning over time (Demmo et al., 2018; Torres et al., 2020). Thus, it is currently unknown whether bipolar disorder is characterized by cognitive stability or progression after illness onset (Van Rheenen et al., 2020). Most likely, both notions are correct. A meta-analysis of studies that included participants with schizophrenia and bipolar disorder in direct comparisons concluded that significant premorbid 
deficits are present in schizophrenia and that both disorders are characterized by cognitive decline after illness onset, with larger impairments in schizophrenia (Trotta, Murray, \& MacCabe., 2015). Indeed, there is evidence for neurodevelopmental and neuroprogressive cognitive trajectories in both disorders (Menkes, Armstrong, Balckford, Heckers, \& Woodward, 2019).

The aim of this study is to provide an independent replication of previous research that has identified distinct cognitive schizophrenia groups using premorbid and current IQ estimates (Weickert et al., 2000; Wells et al., 2015). Through empirical classification, we will expand previous studies by including individuals with bipolar disorder along with participants with schizophrenia. To our knowledge, this is the first study to examine intellectual trajectories in bipolar disorder. Cognitive subgroups will be compared on neuropsychological test results and on measures of functioning and clinical symptoms/psychopathology.

\section{METHODS}

\section{Participants}

Participants recruited to the ongoing TOP study at Oslo University Hospital, Norway, from 2003-2017 were included. In all, 476 healthy control participants (HC), 223 individuals with schizophrenia, and 175 with bipolar disorder were subjected to analyses of neuropsychological, psychopathological, and functional differences across IQ-defined cognitive subgroups. We focused on narrow schizophrenia or bipolar disorder and only included individuals with DSM-IV schizophrenia or bipolar I disorder. Diagnoses were based on the SCID interview (First, Spitzer, Gibbon, \& Williams, 1995) conducted by trained clinical psychologists or medical doctors/psychiatrists. Participants were included regardless of IQ level, but individuals with poor test effort defined as committing $>2$ errors on the forced recognition trial of the California Verbal Learning Test-II (CVLT-II; Delis, Kramer, Kaplan, \& Ober, 2004) were excluded. Further, only those with Norwegian as mother tongue or, if this was not the case, who had completed all formal education in Norway were included. Other exclusion criteria were dyslexia, head trauma requiring hospitalization, or neurological disease. Participants were provided with oral and written information before they signed informed consent and assessed in a clinically stable state. The study was completed in accordance with the Helsinki Declaration and approved by the regional committee for medical research ethics.

\section{Measures}

\section{Clinical measures}

Psychopathology was assessed with four instruments. The Global Assessment of Functioning, symptoms subscale (GAF-s; Pedersen, Hagtvedt, \& Karterud, 2007) provided a measure of global symptom load. Positive and negative symptoms were indexed by the Positive and Negative Syndrome Scale (PANSS; Kay, Fizsbein, \& Opler, 1987). Depression was assessed with the Inventory of Depressive Symptoms, clinician rated (IDS-C; Rush, Guillon, Basco, Jarrett, \& Trivedi, 1996) and mania with the Young Mania Rating Scale (YMRS; Young, Biggs, Ziegler, \& Meyer, 1978). See Table 1 for clinical information. The mean depression scores indicate mild depression, whereas the mania scores are in line with a normal (non-manic) state (definition of euthymia: IDS-C $\leq 12$; $\mathrm{YMRS}<8$ : Tohen et al., 2009).

\section{Neuropsychological tests}

Current IQ was assessed with the Wechsler Abbreviated Scale of Intelligence (WASI; Wechsler, 2007). Premorbid IQ was measured with the Norwegian version of the National Adult Reading Test (NART; Sundet \& Vaskinn, 2008). See Table 1 for the IQ scores of the three participant groups. We attribute the somewhat high IQ scores to the properties of the Norwegian WASI, which uses US norms, suspected to yield higher IQs than versions used in other countries (Siqveland, Dalsbø, Harboe, \& Leiknes, 2014). Our remaining neuropsychological test battery was constructed to cover domains relevant to severe mental disorder. Attention was assessed with Digit Span (forward and backward collapsed) (Wechsler Adult Intelligent Test III (WAIS-III; Wechsler, 2003). Digit Symbol, also from WAIS-III, was the measure of Psychomotor speed. Motor function was measured with the Grooved Pegboard test (Kløve, 1963). Verbal memory was assessed with the long delay free recall condition of the CVLT-II (Delis et al., 2004). The total number of list A words recalled during the learning trials on the CVLT-II was our measure of verbal learning along with the Logical Memory Test from Wechsler Memory Scale (WMS-III; Wechsler, Wycherly, \& Benjamin, 1998), whereas visual learning was assessed with Rey-Osterrieth Complex Figure Test (RCFT) (Meyers $\&$ Meyers, 1995). Working memory was indexed by Letter Number Sequencing (LNS) from WAIS-III. Finally, two subtests from the Delis-Kaplan Executive Function System (D-KEFS) (Delis, Kaplan, \& Kramer, 2005) were included as measures of executive function: Category Fluency from the Verbal Fluency Test and the Stroop condition from the Color-Word Interference Test. The RCFT and LNS were added to the battery after some time, thereby yielding missing scores for some participants. The exact number of participants that underwent assessment with any given test is provided in Table 3.

\section{NART and premorbid IQ}

A previously recommended NART formula was based on normative data from a cohort of healthy control participants (HC) $(n=270)$, validated in samples of individuals with schizophrenia spectrum $(n=110)$ and bipolar spectrum 
Table 1. Demographic and clinical characteristics, functioning and IQ in participants with schizophrenia or bipolar I disorder and in healthy participants

\begin{tabular}{|c|c|c|c|c|}
\hline & $\begin{array}{c}\text { Participants with } \\
\text { schizophrenia } \\
n=223\end{array}$ & $\begin{array}{c}\text { Participants with bipolar I } \\
\text { disorder } \\
n=175\end{array}$ & $\begin{array}{l}\text { Healthy control } \\
\text { participants } \\
n=476\end{array}$ & Statistic \\
\hline \multicolumn{5}{|l|}{ Demographics } \\
\hline Age & $30.8(9.5)$ & $34.0(12.3)$ & $34.6(10.1)$ & $\begin{array}{l}\mathrm{F}=10.1, p<0.001 \\
\mathrm{SZ}<\mathrm{BD}, \mathrm{HC}\end{array}$ \\
\hline Gender $(\mathrm{m} / \mathrm{f})$ & $134 / 89$ & $79 / 96$ & $232 / 244$ & $\mathrm{x}^{2}=10.8, p=0.005$ \\
\hline WASI IQ & $103.0(13.8)$ & $107.7(12.4)$ & $113.2(9.6)$ & $\begin{array}{l}\mathrm{F}=63.0, p<0.001 \\
\mathrm{SZ}<\mathrm{BD}<\mathrm{HC}\end{array}$ \\
\hline NART IQ & $110.1(7.0)$ & $112.2(6.6)$ & $114.1(5.4)$ & $\begin{array}{l}\mathrm{F}=32.3, p<0.001 \\
\mathrm{SZ}<\mathrm{BD}<\mathrm{HC}\end{array}$ \\
\hline IQ decline & $7.2(10.8)$ & $4.5(10.2)$ & $0.8(8.5)$ & $\begin{array}{l}\mathrm{F}=35.6, p<0.001 \\
\mathrm{SZ}>\mathrm{BD}>\mathrm{HC}\end{array}$ \\
\hline Education (years) & $12.3(2.4)$ & $13.4(2.4)$ & $14.2(2.3)$ & $\begin{array}{l}\mathrm{F}=50.0, p<0.001 \\
\mathrm{SZ}<\mathrm{BD}<\mathrm{HC}\end{array}$ \\
\hline \multicolumn{5}{|l|}{ Clinical characteristics } \\
\hline GAF-s & $40.6(10.2)$ & $56.6(12.8)$ & - & $\mathrm{t}=-13.9, p<0.001$ \\
\hline PANSS positive & $15.4(5.3)^{1}$ & $10.3(3.8)^{2}$ & - & $\mathrm{t}=10.7, p<0.001$ \\
\hline PANSS negative & $16.2(6.3)^{3}$ & $10.5(3.9)^{2}$ & - & $\mathrm{t}=10.5, p<0.001$ \\
\hline IDS-C & $16.0(10.9)^{4}$ & $15.5(11.6)^{5}$ & - & $\mathrm{t}=0.4, p=0.722$ \\
\hline YMRS & $5.4(5.3)^{6}$ & $3.4(5.1)^{2}$ & - & $\mathrm{t}=3.8, p<0.001$ \\
\hline \multicolumn{5}{|l|}{$\begin{array}{l}\text { Antipsychotic medication } \\
n(\%)\end{array}$} \\
\hline -atypical & $184(82.5 \%)$ & $98(56 \%)$ & - & $\mathrm{x}^{2}=48.3, p<0.001$ \\
\hline -typical & $15(6.7 \%)$ & $6(3.4 \%)$ & - & \\
\hline $\begin{array}{l}\text { Antiepileptic medication } \\
n(\%)\end{array}$ & $31(13.9 \%)$ & $78(44.6 \%)$ & - & $\mathrm{x}^{2}=46.4, p<0.001$ \\
\hline Lithium $n(\%)$ & $0(0 \%)$ & $38(21.7 \%)$ & - & $\mathrm{x}^{2}=53.5, p<0.001$ \\
\hline Antidepressants $n(\%)$ & $75(32.3 \%)$ & $57(32.6 \%)$ & - & $\mathrm{x}^{2}<0.1, p=0.952$ \\
\hline \multicolumn{5}{|l|}{ Functioning } \\
\hline GAF-f & $42.1(9.7)$ & $53.0(13.1)$ & - & $\mathrm{t}=-9.57, p<0.001$ \\
\hline SFS withdrawal & $100.7(10.7)^{7}$ & $106.0(11.3)^{8}$ & $120.1(8.7)$ & $\begin{array}{l}\mathrm{F}=331.3, p<0.001 \\
\mathrm{SZ}<\mathrm{BD}<\mathrm{HC}\end{array}$ \\
\hline $\begin{array}{l}\text { SFS interpersonal } \\
\text { communication }\end{array}$ & $113.1(18.3)^{7}$ & $119.5(20.1)^{8}$ & $138.4(12.1)$ & $\begin{array}{l}\mathrm{F}=223.2, p<0.001 \\
\mathrm{SZ}<\mathrm{BD}<\mathrm{HC}\end{array}$ \\
\hline SFS prosocial behavior & $103.9(11.4)^{9}$ & $106.0(11.8)^{8}$ & $117.9(8.2)$ & $\begin{array}{l}\mathrm{F}=185.9, p<0.001 \\
\mathrm{SZ}, \mathrm{BD}<\mathrm{HC}\end{array}$ \\
\hline SFS recreation & $108.3(12.8)^{7}$ & $109.6(11.9)^{8}$ & $121.8(5.0)$ & $\begin{array}{l}\mathrm{F}=213.4, p<0.001 \\
\mathrm{SZ}, \mathrm{BD}<\mathrm{HC}\end{array}$ \\
\hline $\begin{array}{l}\text { SFS independence } \\
\text { competence }\end{array}$ & $105.5(14.3)^{7}$ & $110.6(16.1)^{8}$ & $126.5(12.5)$ & $\begin{array}{l}\mathrm{F}=199.7, p<0.001 \\
\mathrm{SZ}<\mathrm{BD}<\mathrm{HC}\end{array}$ \\
\hline $\begin{array}{l}\text { SFS independence } \\
\text { performance }\end{array}$ & $105.7(13.9)^{7}$ & $112.1(14.3)^{8}$ & $123.4(10.0)$ & $\begin{array}{l}\mathrm{F}=172.9, p<0.001 \\
\mathrm{SZ}<\mathrm{BD}<\mathrm{HC}\end{array}$ \\
\hline SFS employment ${ }^{10}$ & $104.0(11.3)$ & $110.1(12.3)^{11}$ & $121.6(3.3)$ & $\begin{array}{l}\mathrm{F}=360.8, p<0.001 \\
\mathrm{SZ}<\mathrm{BD}<\mathrm{HC}\end{array}$ \\
\hline
\end{tabular}

GAF-s = Global Assessment of Functioning, symptoms subscale. PANSS = Positive and Negative Syndrome Scale. YMRS = Young Mania Rating Scale. IDS-C $=$ Inventory of Depressive Symptoms-Clinician rated. GAF- $\mathrm{f}=$ Global Assessment of Functioning, function subscale. SFS $=$ Social Functioning Scale. ${ }^{1} n=220$ due to missing data; ${ }^{2} n=174$ due to missing data; ${ }^{3} n=221$ due to missing data; ${ }^{4} n=178$ due to missing data; $;{ }^{5} n=166$ due to missing data; $;{ }^{6} n=211$ due to missing data; ${ }^{7} n=210$ due to missing data; ${ }^{8} n=173$ due to missing data; ${ }^{9} n=209$ due to missing data; ${ }^{10} n=207$ due to missing data; ${ }^{11} n=172$ due to missing data.

$(n=100)$ disorders, all from our center (Sundet \& Vaskinn, 2008). The formula used number of NART errors, age, and education and yielded possible premorbid IQ scores from 82.0 to 126.6. Other formulas, without age and education, were also presented, but were not recommended for use (Sundet \&
Vaskinn, 2008). The publication of several formulas may have caused some confusion. For the current study, we simplified the previously recommended formula, without compromising the range of possible premorbid IQ scores, by excluding education from the regression equation: 


$$
\begin{aligned}
\text { NART IQ }= & 129.5+(\text { NART errors } \mathrm{x}-0.79) \\
& +(\text { Age } \mathrm{x}-0.12)
\end{aligned}
$$

This was done using a new, larger, and independent sample of HCs $(n=613)$, included after the first Norwegian NART publication (Sundet \& Vaskinn, 2008), that is, 2008-2017. The new, simpler formula yielded a comparable range (82.2-127.3) to the old formula, but a wider range compared to a formula without age (87.8-124.8). This new formula was validated in individuals with schizophrenia $(n=102)$ or bipolar I disorder ( $n=101$ ), also included from 2008 to 2017 , by comparing the difference between premorbid IQ, current IQ, and IQ decline between HCs and the two clinical groups. This was done using three separate univariate analyses of variance (ANOVA). See Supplementary Table 1 for demographic, clinical, and IQ data for these three participant groups.

\section{Measures of functioning}

Global functioning was assessed with GAF, function subscale (GAF-f; Pedersen et al., 2007). Social functioning was measured with the Norwegian version of the Social Functioning Scale (SFS; Birchwood, Smith, Cochrane, Wetton, \& Copestake, 1994), validated for schizophrenia and bipolar disorder (Hellvin et al., 2010). SFS is a self-report questionnaire consisting of seven scales that assess various social behaviors. All seven scales were used. See Table 1 for information on functioning.

\section{Statistical analyses}

All analyses were done using SPSS, version 25.0. The cluster analyses were conducted in participants with schizophrenia and bipolar I disorder $(n=398)$. First, in line with previous studies, participants were subjected to hierarchical cluster analysis with complete linkage (furthest neighbor) and squared Euclidian distances using NART IQ and WASI IQ. This was done first in participants with schizophrenia ( $n$ $=223$ ) or bipolar I disorder $(n=175)$, separately, then for the two diagnostic categories, collapsed. A consensus decision on number of clusters, that is, cognitive subgroups, was undertaken in two steps. First, the dendrograms and scree plots (of agglomeration coefficients) from the hierarchical cluster analyses were subjected to visual inspection. This included the "elbow test" for the scree plots. Second, variance ratio criterions (VRCs) according to Calinski and Harabasz (1974) were calculated from K-means cluster analyses with number of clusters ranging from two to five. VRC is one of many clustering validity criteria and was found to rank among the best in an investigation of 40 such criteria (Vendramin, Campello, \& Hruschka, 2010). The VRC is defined as:

$$
\frac{S S_{B}}{S S_{W}} \times \frac{N-k}{k-1}
$$

where $N$ is the number of individuals, $k$ is the number of clusters, $\mathrm{SS}_{\mathrm{B}}$ is the between-cluster variation, and $\mathrm{SS}_{\mathrm{W}}$ is the within-cluster variation. VRCs were calculated from the K-means cluster analyses for participants with schizophrenia, with bipolar I disorder, and for the two diagnostic categories, collapsed. Pooled between and within cluster sum of squares $\left(\mathrm{SS}_{\mathrm{B}}\right.$ and $\left.\mathrm{SS}_{\mathrm{W}}\right)$, that is, for WASI and NART collapsed, were used in the VRC calculations. A higher VRC indicates a better cluster solution (Calinski \& Harabasz, 1974; Milligan \& Cooper, 1985). To validate the clusters from the consensus decision in the cross-diagnostic sample, multinomial logistic regression was used to predict cluster membership (dependent variable) in individuals with schizophrenia or bipolar disorder from NART IQ and WASI IQ (independent variables). As an additional validation of the clusters, a multivariate analysis of variance (MANOVA) was performed with the 10 neuropsychological tests as dependent variables and diagnostic group (schizophrenia, bipolar I disorder) and cluster membership (cognitive subgroup) as independent variables. Thereafter, the cross-diagnostic cognitive subgroups yielded from the K-means cluster analysis (with the chosen number of clusters) were subjected to group comparisons using ANOVAs or MANOVAs. Due to missing data on single tests, neuropsychological group differences were investigated with a series of ANOVAs, albeit bonferroni-corrected for multiple comparisons ( $p$-level of $0.05 / 10$ neuropsychological tests $=$ new $p$-level 0.005$)$. GAF-f was examined with an ANOVA, whereas the seven SFS subscales were analyzed with a MANOVA. In case of a significant overall group effect for SFS, follow-up ANOVAs for each SFS subscale were conducted. Finally, the five symptom measures were subjected to five ANOVAs, but with correction for multiple testing $(p$-level of $0.05 / 5$ symptom measures $=$ new $p$-level $0.01)$. HCs $(n=476)$ were included in the statistical analyses of neuropsychological group differences.

\section{RESULTS}

The dendrograms and scree plots from the hierarchical cluster analyses for schizophrenia, bipolar disorder, and the samples collapsed all indicated three clusters (see Supplementary Material for scree plots). The VRCs from the K-means cluster analyses are presented in Supplementary Table 2. For bipolar disorder and the sample collapsed, the highest VRCs appeared for a three-cluster solution. For schizophrenia, the VRCs for two- and three-cluster solutions were almost identical. Since the dendrograms and scree plots were deemed consistent with a three-cluster solution, the consensus decision for schizophrenia was also three clusters. The Kmeans cluster analysis of the whole sample with number " 3 " was used to create three clusters, or cognitive subgroups. See Figure 1 for a graphical presentation of the clusters.

The multinomial logistic regression found the final model with premorbid NART IQ and WASI IQ as predictors for cluster membership to be highly significant $\left(x^{2}=834.6\right.$, df $=4, p<0.001$, Nagelkerke $=1.00)$. The MANOVA yielded 
Table 2. IQ and demographics in cognitive subgroups across diagnostic categories (schizophrenia $n=223$; bipolar disorder $n=175$ ) based on empirical clustering $(n=398)$

\begin{tabular}{|c|c|c|c|c|}
\hline & Cluster 1: Intact & Cluster 2: Intermediate & Cluster 3: Impaired & Statistic \\
\hline $\mathrm{N}$ & $n=145$ & $n=175$ & $n=78$ & - \\
\hline Proportion of sample across diagnoses & $36 \%$ & $44 \%$ & $20 \%$ & - \\
\hline Proportion of schizophrenia sample & $32 \%$ & $42 \%$ & $26 \%$ & - \\
\hline Proportion of bipolar disorder sample & $42 \%$ & $46 \%$ & $12 \%$ & - \\
\hline $\begin{array}{l}\text { Diagnostic distribution: schizophrenia/bipolar } \\
\text { disorder } n(\%)\end{array}$ & $\begin{array}{c}72 / 73 \\
(50 / 50)\end{array}$ & $\begin{array}{c}94 / 81 \\
(54 / 46)\end{array}$ & $\begin{array}{l}57 / 21 \\
(73 / 27)\end{array}$ & $\begin{array}{l}\mathrm{x}^{2}=12.0 \\
p=\mathbf{0 . 0 0 3}\end{array}$ \\
\hline NART IQ Mean (SD) & $116.2(4.8)$ & $109.8(5.4)$ & $104.2(6.0)$ & $\mathrm{F}=138.36$ \\
\hline Min-max & $102.8-123.7$ & $91.9-121.1$ & $91.1-119$ & $\begin{array}{l}\boldsymbol{p}<\mathbf{0 . 0 0 1} \\
1>2>3\end{array}$ \\
\hline WASI IQ Mean (SD) & $118.3(6.5)$ & $103.1(4.5)$ & $85.0(7.2)$ & $\mathrm{F}=837.94$ \\
\hline Min-max & $108-138$ & $92-113$ & $54-95$ & $p<0.001$ \\
\hline IQ decline & - & $6.7(7.0)$ & $19.2(8.3)$ & $\begin{array}{c}1>2>3 \\
\mathrm{~F}=209.71 \\
\boldsymbol{p}<\mathbf{0 . 0 0 1} \\
1<2<3\end{array}$ \\
\hline Gender: $\mathrm{m} / \mathrm{f}$ & $81 / 64$ & $86 / 89$ & $46 / 32$ & $\begin{array}{c}\mathrm{x}^{2}=2.6 \\
p=0.272\end{array}$ \\
\hline Age & $32.2(9.7)$ & $32.3(11.2)$ & $32.0(12.5)$ & $\begin{array}{c}\mathrm{F}=0.02 \\
p=0.977\end{array}$ \\
\hline Education & $13.9(2.4)$ & $12.6(2.3)$ & $11.1(2.0)$ & $\begin{aligned} \mathrm{F} & =40.02 \\
\boldsymbol{p} & <\mathbf{0 . 0 0 1} \\
1 & >2>3\end{aligned}$ \\
\hline
\end{tabular}

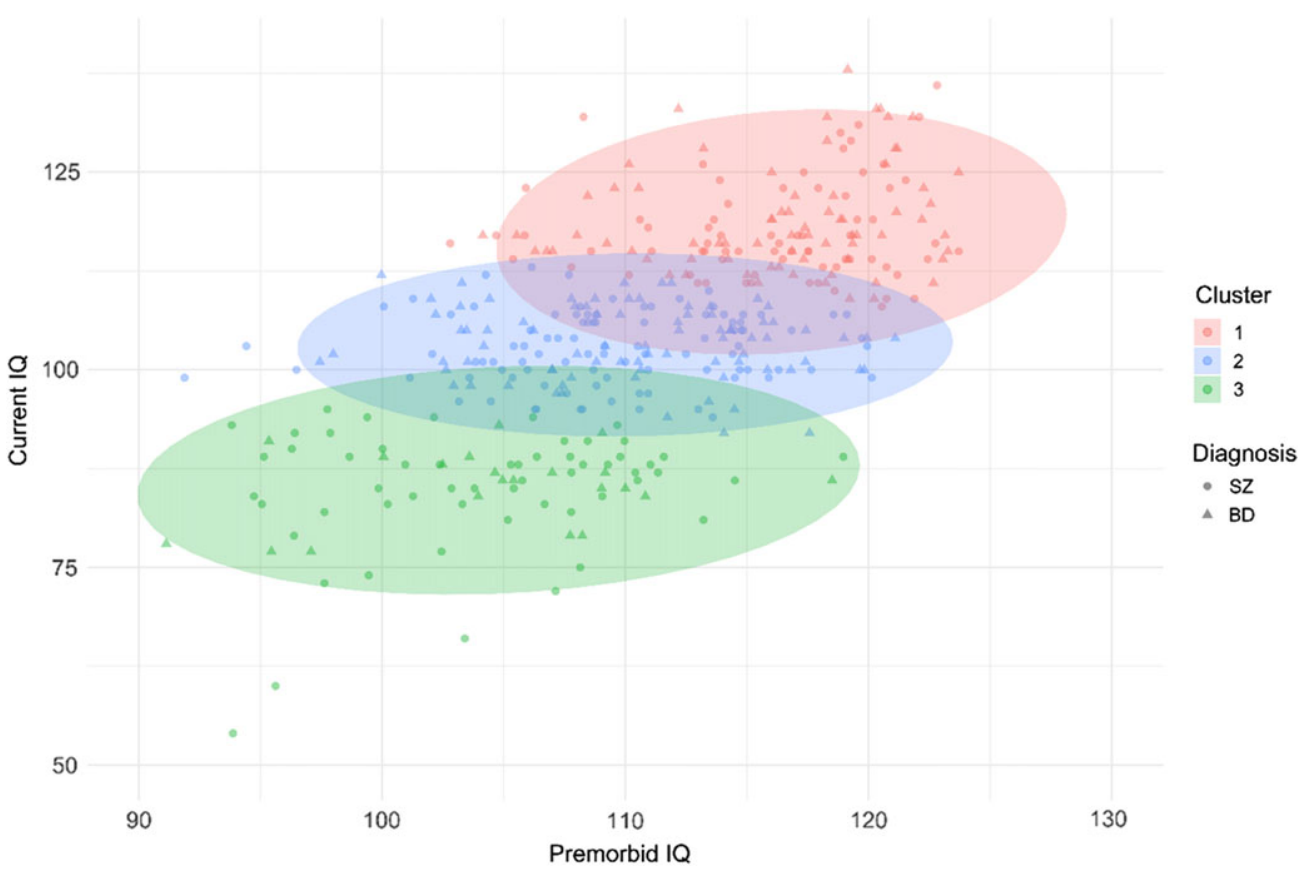

Fig. 1. Cluster plot of the three cognitive subgroups created from current and premorbid IQ scores.

Cluster $1=$ Relatively intact cognitive function. Cluster $2=$ Intermediate cognitive function. Cluster $3=$ Globally impaired cognitive function. $\mathrm{SZ}=$ schizophrenia. $\mathrm{BD}=$ bipolar $\mathrm{I}$ disorder. Current $\mathrm{IQ}=$ Wecshler Abbreviated Scale of Intelligence. Premorbid IQ $=$ National Adult Reading Test.

a highly significant main effect of cluster membership $\left(\mathrm{F}=15.8\right.$, Wilk's Lambda $\left.=0.43, p<0.001, \eta^{2}=0.35\right)$ and a marginally significant main effect of diagnostic group $\left(\mathrm{F}=1.9\right.$, Wilk's Lambda $\left.=0.94, p=0.049, \eta^{2}=0.06\right)$ on neuropsychological test results, lending support to the validity of the empirical clustering. The cluster $x$ group interaction effect was also significant $(\mathrm{F}=2.0$, Wilk's Lambda $=0.88$, $\left.p=0.006, \eta^{2}=0.06\right)$. See Table 2 for the premorbid 
(a)

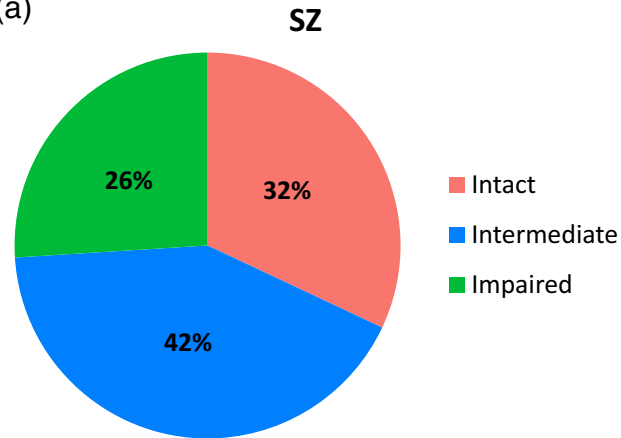

(b)

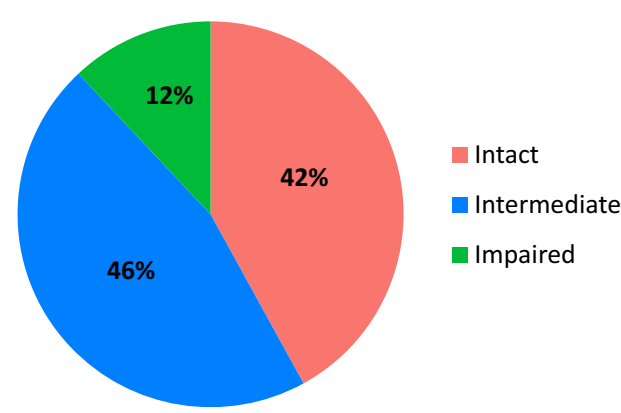

Fig. 2. Distribution of participants falling into each cluster within (a) the schizophrenia sample and (b) the bipolar I disorder sample. $\mathrm{BD}=$ bipolar $\mathrm{I}$ disorder. $\mathrm{SZ}=$ schizophrenia. Intact $=$ Relatively intact cognitive function. Intermediate $=$ Intermediate cognitive function. Impaired = Globally impaired cognitive function.

NART IQ, current WASI IQ, and IQ decline for the three clusters, that is, cognitive subgroups.

Compared to healthy controls, the first cognitive subgroup had normal premorbid IQ (116.2) with no decline from premorbid to current IQ (relatively intact group). The second cognitive subgroup had near-normal premorbid IQ (109.8) and a small decline (6.7 IQ points) from premorbid to current IQ (intermediate group). The third cognitive subgroup had reduced premorbid IQ (104.2) and additionally experienced a substantial decline (19.2 IQ points) from premorbid to current IQ (impaired group). The three cognitive subgroups did not differ in age or gender distribution, but had different length of education (relatively intact $>$ intermediate > impaired). The distribution of participants from the two diagnostic categories differed significantly across clusters $\left(\mathrm{x}^{2}=12.0, p=0.003\right)$. There were more individuals with schizophrenia than individuals with bipolar disorder in the impaired group (73\% versus 27\%), but the other two groups had an equal number of persons from the two diagnostic groups (intermediate group: 54\% versus 46\%; relatively intact group: $50 \%$ versus $50 \%$ ). For the exact distribution of participants see Figure 2 (distribution of clusters within each diagnostic category) and Figure 3 (distribution of diagnostic categories within each cluster).

The cognitive subgroups differed significantly for all neuropsychological tests, corrected for multiple comparisons (relatively intact $>$ intermediate $>$ impaired). The relatively intact group performed significantly below HCs for

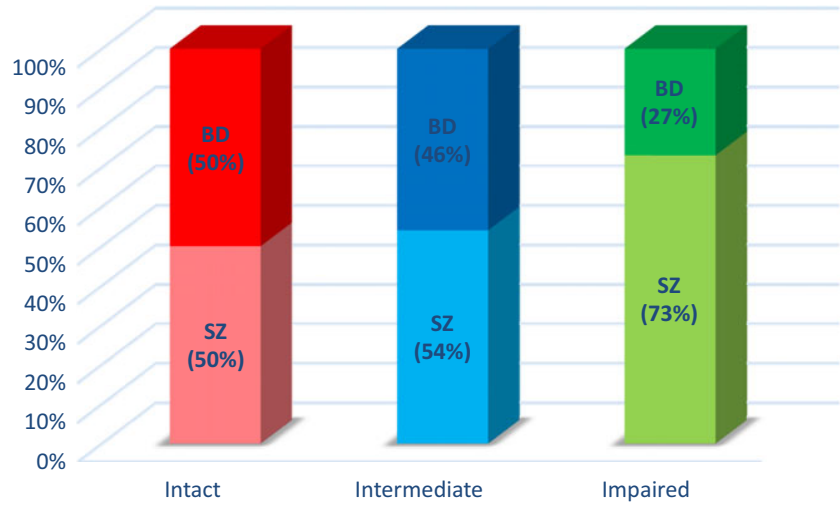

Fig. 3. Proportion of participants with schizophrenia and bipolar disorder in the three cognitive clusters.

$\mathrm{BD}=$ bipolar $\mathrm{I}$ disorder. $\mathrm{SZ}=$ schizophrenia. Intact $=$ Relatively intact cognitive function. Intermediate $=$ Intermediate cognitive function. Impaired = Globally impaired cognitive function.

psychomotor speed, motor function, and executive function (see Table 3 and Figure 4).

For functioning, a significant group difference appeared for global functioning, GAF-f (relatively intact $>$ intermediate $>$ impaired), but not for SFS (see Table 4).

Finally, for psychopathology, there were significant group differences for global symptom load (GAF-s) and for positive and negative symptoms as assessed with the PANSS; with the impaired group experiencing more severe symptoms than the other two groups. There were no differences for depressive or manic symptoms (see Table 5).

\section{DISCUSSION}

This study found that a sample consisting of individuals with schizophrenia or bipolar I disorder could be divided into three distinct cognitive subgroups based on the intellectual trajectory from the premorbid phase to after illness onset: a relatively intact group, an intermediate group with mildmoderate cognitive impairment, and a globally impaired group. These groups differed in neuropsychological profile, for positive and negative symptoms, and for global functioning.

Our study replicates previous findings in two ways. First, by identifying three distinguishable cognitive subgroups that cut across diagnostic boundaries (Van Rheenen et al., 2017). This suggests that the same cognitive heterogeneity is present regardless of whether the diagnosis is schizophrenia or bipolar I disorder, although there were more individuals with schizophrenia in the impaired cognitive subgroup. Second, our results confirm the existence of three different intellectual trajectories from the premorbid phase to after illness onset in schizophrenia (Weickert et al., 2000). However, our results also differ from earlier work (Weickert et al, 2000; Van Rheenen et al., 2017), instead providing new insights. We show that the three cognitive subgroups, across severe mental illness, can be identified not only using neuropsychological tests that assess current functioning (Burdick et al., 2014; Van Rheenen et al., 2017) but also with tests that identify 
Table 3. Neuropsychological test performance (standardized scores) in healthy controls and in cognitive subgroups (with schizophrenia or bipolar disorder)

\begin{tabular}{|c|c|c|c|c|c|}
\hline & $\begin{array}{c}\text { Healthy control } \\
\text { participants } \\
n=476\end{array}$ & $\begin{array}{c}\text { Cluster 1: } \\
\text { Intact } \\
n=145\end{array}$ & $\begin{array}{c}\text { Cluster 2: } \\
\text { Intermediate } \\
n=175\end{array}$ & $\begin{array}{c}\text { Cluster 3: } \\
\text { Impaired } \\
n=78\end{array}$ & $\begin{array}{l}\text { Statistic } \\
\text { Between group- } \\
\text { comparison }\end{array}$ \\
\hline Digit Span (SS) & $9.5(2.4)$ & $9.8(2.3)$ & $8.0(1.7)$ & $6.8(1.9)$ & $\begin{array}{c}\mathrm{F}=50.2 \\
p<0.001^{*} \\
\eta_{\mathrm{p}}^{2}=0.15 \\
\mathrm{HC}, 1>2>3\end{array}$ \\
\hline Digit Symbol (SS) & $10.4(2.5)$ & $9.1(2.3)$ & $7.1(2.1)$ & $5.9(1.8)$ & $\begin{array}{c}\mathrm{F}=145.0 \\
p<0.001^{*} \\
\eta_{\mathrm{p}}^{2}=0.33 \\
\mathrm{HC}>1>2>3\end{array}$ \\
\hline Grooved Pegboard Test $(\mathrm{T})$ & $48.1(8.7)$ & $43.4(9.9)$ & $37.8(10.9)$ & $33.1(9.9)$ & $\begin{array}{c}\mathrm{F}=89.5 \\
p<0.001^{*} \\
\eta_{\mathrm{p}}^{2}=0.24 \\
\mathrm{HC}>1>2>3\end{array}$ \\
\hline CVLT-II learning (T) & $56.5(10.3)$ & $55.4(11.2)$ & $48.9(10.7)$ & $41.4(12.0)$ & $\begin{array}{c}\mathrm{F}=58.8 \\
p<0.001 * \\
\eta_{\mathrm{p}}{ }^{2}=0.17 \\
\mathrm{HC}, 1>2>3\end{array}$ \\
\hline CVLT-II delayed recall (z) & $0.56(0.95)$ & $0.36(0.93)$ & $-0.06(1.02)$ & $-0.87(1.25)$ & $\begin{array}{c}\mathrm{F}=54.3 \\
p<0.001 * \\
\eta_{\mathrm{p}}{ }^{2}=0.16 \\
\mathrm{HC}, 1>2>3\end{array}$ \\
\hline Logical Memory learning (SS) & $10.8(2.5)$ & $10.9(2.8)$ & $8.6(2.5)$ & $6.8(2.4)$ & $\begin{array}{c}\mathrm{F}=80.2 \\
p<0.001^{*} \\
\eta_{\mathrm{p}}^{2}=0.22 \\
\mathrm{HC}, 1>2>3\end{array}$ \\
\hline $\begin{array}{l}\text { Rey-Oesterrith Complex } \\
\text { Figure Test }(\mathrm{T})\end{array}$ & $49.0(12.9)$ & $46.6(14.0)$ & $38.0(12.8)$ & $28.2(15.7)$ & $\begin{array}{c}\mathrm{F}=60.4 \\
p<0.001^{*} \\
\eta_{\mathrm{p}}^{2}=0.20 \\
\mathrm{HC}, 1>2>3\end{array}$ \\
\hline $\begin{array}{l}\text { Letter Number } \\
\quad \text { Sequencing (SS) }\end{array}$ & $10.9(2.8)$ & $10.2(2.5)$ & $8.2(2.2)$ & $6.7(2.0)$ & $\begin{array}{c}\mathrm{F}=73.6 \\
p<0.001^{*} \\
\eta_{\mathrm{p}}{ }^{2}=0.22 \\
\mathrm{HC}, 1>2>3\end{array}$ \\
\hline Category Fluency (SS) & $13.9(3.1)$ & $13.1(3.6)$ & $9.9(3.4)$ & $8.5(3.6)$ & $\begin{array}{c}\mathrm{F}=105.4 \\
p<0.001^{*} \\
\eta_{\mathrm{p}}^{2}=0.27 \\
\mathrm{HC}>1>2>3\end{array}$ \\
\hline $\begin{array}{l}\text { Color-Word Interference Test } \\
\text { (SS) }\end{array}$ & $11.0(2.4)$ & $10.0(2.6)$ & $8.4(3.3)$ & $6.9(3.8)$ & $\begin{array}{c}\mathrm{F}=72.4 \\
p<0.001^{*} \\
\eta_{\mathrm{p}}^{2}=0.20 \\
\mathrm{HC}>1>2>3\end{array}$ \\
\hline
\end{tabular}

*Significant after bonferroni correction for multiple comparisons: new $p$-value $(0.05 / 10)=0.005$.

Digit Span: Cluster $3 n=77$. Digit Symbol: Cluster $2 n=174$; Cluster $3 n=77$. Grooved Pegboard: Healthy controls $n=474$; Cluster $2 n=173$; Cluster $3 n=77$. CVLT-II: Healthy controls $n=475$; Cluster $1 n=144$. Logical Memory: Healthy controls $n=474$; Cluster $1 n=142$; Cluster $2 n=173$; Cluster $3 n$ $=77$. Rey-Oesterrith Complex Figure Test: Healthy controls $n=419$; Cluster $1 n=121$; Cluster $2 n=145$; Cluster $3 n=63$. Letter Number Span: Healthy controls $n=455$; Cluster $1 n=119$; Cluster $2 n=140$; Cluster $3 n=63$. Category Fluency: Healthy controls $n=475$. Color-Word Interference Test: Healthy controls $n=473$.

cognitive development from the premorbid phase to after illness onset. In fact, the current literature base suggests that this tripartition does not depend on the neuropsychological measures used (Carruthers et al., 2019a). Further support for this was recently provided by Carruthers et al. (2019b) who identified three cognitive subgroups in a schizophrenia spectrum disorder sample using the Wisconsin Card Sorting Test to examine executive function. Our results also diverge from earlier studies of intellectual trajectories. Whereas two of our empirically derived cognitive subgroups were characterized by a decline (intermediate: 6.7 points, impaired: 19.2 points), this was the case only for the deteriorated group 
Table 4. Global and social functioning in cognitive subgroups

\begin{tabular}{|c|c|c|c|c|}
\hline & $\begin{array}{c}\text { Cluster 1: } \\
\text { Intact } \\
n=145\end{array}$ & $\begin{array}{l}\text { Cluster 2: } \\
\text { Intermediate } \\
n=175\end{array}$ & $\begin{array}{c}\text { Cluster 3: } \\
\text { Impaired } \\
n=78\end{array}$ & Statistic \\
\hline GAF-f & $49.6(12.9)$ & $46.7(12.5)$ & $42.2(10.8)$ & $\begin{array}{c}\mathrm{F}=9.11, p<0.001 \\
\eta_{\mathrm{p}}^{2}=0.04 \\
1,2>3\end{array}$ \\
\hline SFS withdrawal & $102.7(10.7)$ & $103.9(11.5)$ & $101.8(11.9)$ & \multirow{7}{*}{$\begin{array}{c}\text { Wilks Lambda }=0.94 \\
\mathrm{~F}=1.53, p=0.095 \\
\eta_{\mathrm{p}}{ }^{2}=0.03\end{array}$} \\
\hline SFS interpersonal communication & $116.5(20.0)$ & $116.3(19.3)$ & $113.8(18.8)$ & \\
\hline SFS prosocial behavior & $106.3(11.7)$ & $104.1(11.6)$ & $103.4(11.5)$ & \\
\hline SFS recreation & $110.4(10.8)$ & $108.9(13.2)$ & $105.8(13.1)$ & \\
\hline SFS independence competence & $109.3(14.8)$ & $107.1(15.3)$ & $105.7(16.0)$ & \\
\hline SFS independence performance & $109.2(13.3)$ & $109.6(14.4)$ & $104.7(16.1)$ & \\
\hline SFS employment & $108.3(10.8)$ & $106.4(12.8)$ & $105.1(12.3)$ & \\
\hline
\end{tabular}

GAF-f $=$ Global Assessment of Functioning, function subscale. SFS $=$ Social Functioning Scale: Cluster $1 n=136$; Cluster $2 n=169$; Cluster $3 n=73$.

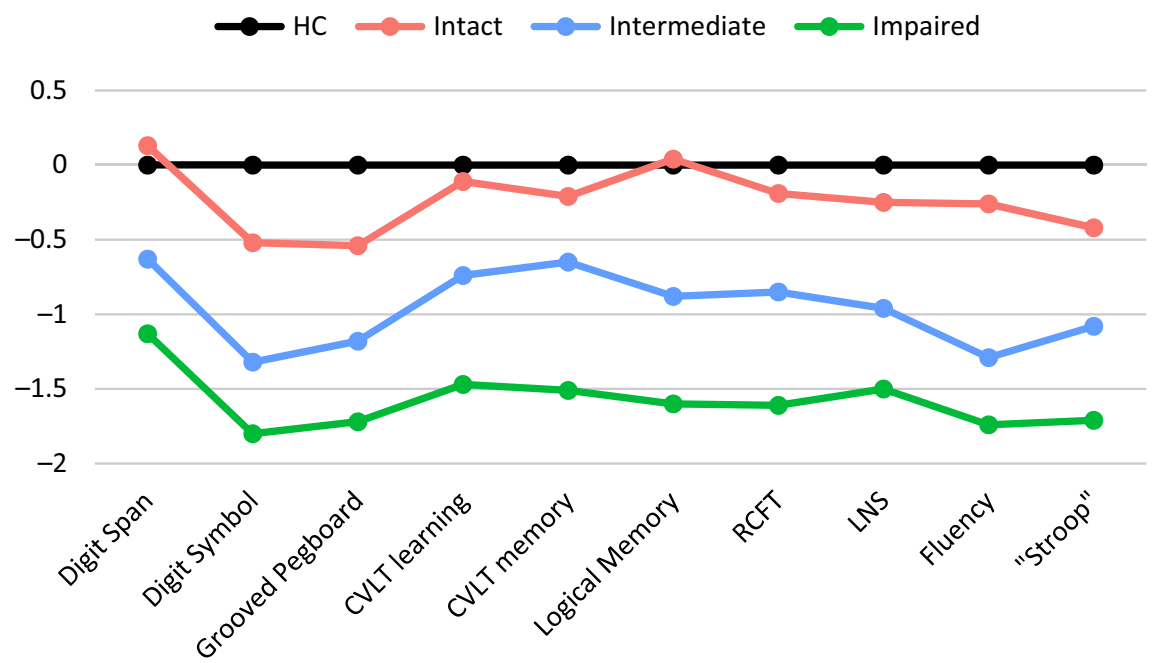

Fig. 4. Neuropsychological profile of the three cognitive subgroups: relatively intact cognitive function, intermediate cognitive function, and globally impaired cognitive function.

CVLT $=$ California Verbal Learning Test. RCFT $=$ Rey-Oesterrith Complex Figure Test. LNS $=$ Letter Number Span. Fluency $=$ Category Fluency. "Stroop" = Color-Word Interference Test.

( $\geq 10$ points) in Weickert et al's (2000) study. The most obvious difference between our study and Weickert et al.'s (2000) study is our inclusion of individuals with bipolar disorder in addition to those with schizophrenia. This can, however, not explain the diverging premorbid/current IQ patterns, since we conducted the analyses also in the two diagnostic groups separately. A more plausible explanation for the differences in premorbid/current IQ patterns is the use of a predefined cutoff of $\geq 10$ points decline in Weickert et al.'s (2000) clinical classification criteria, whereas our empirical approach had no a priori assumptions of such cutoffs. Further, Weickert and colleagues (2000) used an IQ measure where both processing speed and working memory were represented. We used the WASI which does not include these indexes. Due to these issues, a direct comparison of the exact premorbid/current IQ patterns may not be entirely justified.
The results of our study suggest that information regarding the cognitive course from pre- to post illness onset is relevant for the understanding of cognitive heterogeneity also in bipolar I disorder. This is, as far as we know, the first study of intellectual trajectories using premorbid and current IQ measures in bipolar disorder. The findings of three cognitive subgroups align with the existing literature indicative of substantial cognitive heterogeneity in bipolar disorder. This heterogeneity is seen in the U-shaped risk of the disorder, where both high and low IQ increase the risk (Parellada et al., 2017), and in inconsistent results regarding the presence of neuroprogression (Sheffield et al., 2018) or cognitive stability (Torres et al., 2020) over time. Whereas we found some individuals with bipolar disorder to be characterized by cognitive stability, others experienced decline, some of them substantially. Thus, our results support the existence of both cognitive stability as well as neuroprogression in 
Table 5. Clinical symptoms in cognitive subgroups

\begin{tabular}{|c|c|c|c|c|}
\hline & $\begin{array}{c}\text { Cluster 1: } \\
\text { Intact } \\
n=145\end{array}$ & $\begin{array}{l}\text { Cluster 2: } \\
\text { Intermediate } \\
n=175\end{array}$ & $\begin{array}{c}\text { Cluster 3: } \\
\text { Impaired } \\
n=78\end{array}$ & Statistic \\
\hline GAF-s & $50.7(14.4)$ & $47.6(13.2)$ & $42.1(13.0)$ & $\begin{array}{c}\mathrm{F}=10.16 \\
p<0.001^{*} \\
\eta_{\mathrm{p}}^{2}=0.05 \\
1,2>3\end{array}$ \\
\hline $\begin{array}{l}\text { PANSS } \\
\text { positive }\end{array}$ & $12.6(5.0)$ & $12.8(5.4)$ & $15.0(5.5)$ & $\begin{array}{c}\mathrm{F}=6.12 \\
p=0.002^{*} \\
\eta_{\mathrm{p}}^{2}=0.03 \\
1,2<3\end{array}$ \\
\hline $\begin{array}{l}\text { PANSS } \\
\text { negative }\end{array}$ & $12.3(5.3)$ & $13.6(5.9)$ & $16.3(6.8)$ & $\begin{array}{c}\mathrm{F}=11.28 \\
p<0.001^{*} \\
\eta_{\mathrm{p}}^{2}=0.05 \\
1,2<3\end{array}$ \\
\hline YMRS & $4.3(5.0)$ & $4.4(5.6)$ & $5.0(5.2)$ & $\begin{array}{c}\mathrm{F}=0.55 \\
p=0.579 \\
\eta_{\mathrm{p}}{ }^{2}<0.01\end{array}$ \\
\hline IDS-C & $15.1(10.0)$ & $16.0(12.0)$ & $16.3(11.8)$ & $\begin{array}{c}\mathrm{F}=0.33 \\
p=0.722 \\
\eta_{\mathrm{p}}{ }^{2}<0.01\end{array}$ \\
\hline
\end{tabular}

*Significant after bonferroni correction for multiple comparisons: new $p$-value $(0.05 / 5)=0.01$.

GAF $-\mathrm{s}=$ Global Assessment of Functioning, symptoms subscale. PANSS $=$ Positive and Negative Syndrome Scale: Cluster $1 n=143$; Cluster $2 n=173$. YMRS $=$ Young Mania Rating Scale: Cluster $1 n=141$; Cluster $2 n=168$; Cluster $3 n=76$. IDS-C = Inventory of Depressive SymptomsClinician rated: Cluster $1 n=126$; Cluster $2 n=153$; Cluster $3 n=65$.

bipolar disorder, pointing to substantial cognitive heterogeneity within this disorder (Van Rheenen et al., 2020).

Interestingly, we identified a relatively intact group performing largely in line with HCs. This could be interpreted as evidence against the view that cognitive impairment is a core feature of severe mental disorder (Green, Horan \& Lee, 2019). It should be noted, however, that this relatively intact cognitive subgroup performed significantly below HCs for neuropsychological tests with a speeded component, that is, psychomotor speed, motor function, and executive function. We interpret this as evidence that even high-functioning individuals with severe mental illness have some degree of cognitive impairment. This is in accordance with previous findings that $98 \%$ of persons with schizophrenia perform worse on neuropsychological tests than expected from maternal education or premorbid IQ (Keefe, Eesley \& Poe, 2005) and that individuals with superior intelligence and schizophrenia have neurocognitive decrements compared to IQ-matched HCs (Vaskinn et al., 2014). That the worse performance appeared for neuropsychological tests that depend on psychomotor speed is also in agreement with the finding that this cognitive domain is more affected than others (Dickinson, Ramsey \& Gold, 2007; Schaefer, Giangrande, Weinberger, \& Dickinson, 2013).

Our relatively intact group comprised more than a third of our participants with severe mental disorder. This subgroup was larger than in other schizophrenia studies where around $25 \%$ present with relatively intact cognition (Weickert et al.,
2000; Carruthers et al., 2019a). We would like to suggest two possible explanations. First, the relatively intact subgroup may be larger in bipolar disorder samples. For instance, Burdick and colleagues (2014) found that $32 \%$ belonged to the cognitively intact group. Second, the younger age of our participants may have contributed to a larger proportion of the sample being allocated to the relatively intact subgroup. A cross-diagnostic study of schizophrenia and bipolar disorder found significant age differences between the relatively intact $(34.0+10.9$ years $)$ and the impaired $(40.6+$ 11.2 years) cognitive subgroups (Lewandowski et al., 2014). Our participants were younger (32 years) without differences between cognitive subgroups. Our speculation, therefore, is that the inclusion of individuals with bipolar disorder, in combination with the age of our sample, has contributed to the larger relatively intact group compared to other studies.

Since schizophrenia is characterized by more severe cognitive impairment than bipolar disorder (Bortolato et al., 2015), the fact that there were more individuals with schizophrenia than with bipolar disorder in the impaired group was expected. Interestingly, however, $32 \%$ of the schizophrenia sample belonged to the relatively intact group, and the distribution of individuals with schizophrenia or with bipolar I disorder within this cognitive cluster was even. Given studies that have found good premorbid abilities to be associated with bipolar disorder (Koenen et al., 2009; MacCabe et al., 2010; Smith et al., 2015), it is not surprising that $42 \%$ of the individuals with this diagnosis belonged to a relatively intact cognitive subgroup. But the fact that one-third of the schizophrenia sample, and just as many people with schizophrenia as with bipolar disorder, presented with relatively intact cognition is evidence that cognitive heterogeneity within schizophrenia is substantial. A diagnosis of schizophrenia alone, therefore, provides little information concerning cognitive abilities at the individual level.

Validation for the meaningfulness of the three cognitive clusters was provided by significant group differences in positive, negative, and global symptoms and in global functioning. We believe that nonsignificant differences in affective symptoms may be due to low symptom load as participants at our center are usually assessed in a euthymic or near-euthymic state. Surprisingly, we did not identify any group differences in social functioning. A possible reason is that the self-report format of the measure used, the SFS. Perhaps social functioning, if assessed by an observer, would have yielded significant group differences. This would be in line with studies that have shown that many with schizophrenia inaccurately rate their own functioning, compared to the ratings of case managers (Bowie et al., 2007) or interviewers (Sabbag et al., 2012). The allocation of a person to a specific cognitive cluster did not depend on their age or their gender, as no significant differences of the distribution of these variables were found.

Our study implies that the psychiatric diagnosis that specifies which severe mental disorder a person suffers from falls short of providing any useful information about that person's neuropsychological profile. This underscores the need to 
conduct a neuropsychological examination as part of structured assessment. This is especially important since neuropsychological status has been found to impact functioning in both schizophrenia (Green et al., 2004) and in bipolar disorder (Baune \& Malhi, 2015).

Among the limitations of the study is the relatively high mean IQ of our participants, both HCs and participants with clinical diagnoses. The WASI IQs are higher than in studies from other countries and contexts. An evaluation of the Norwegian WASI, which uses US norms, concluded that it probably overestimates IQ (Siqveland et al., 2014). Therefore, we believe that the high WASI IQ is likely a result of the properties of the test and the standardization of it, not that our participants in fact have cognitive skills above the population average. The mean scores of our HCs for the neuropsychological tests indicate that this is the case. As can be seen in Table 4, the HCs perform very close to the standardized means. Finally, assessment of premorbid functioning using retrospective measures such as the NART has some degree of uncertainty compared to assessment conducted concurrently prior to illness onset.

In conclusion, three cognitive subgroups resulted from cluster analysis of test performance on measures of premorbid and current intelligence in a combined sample of individuals with schizophrenia or bipolar I disorder. Differences in neuropsychological functioning, symptom level, and global functioning between the groups of relatively intact, intermediate, and globally impaired cognition suggest that these are meaningful and valid groups. The fact that they cut across diagnostic categories underscores the need to move beyond the diagnosis when planning treatment interventions and in scientific studies of their possible etiological and pathophysiological underpinnings.

\section{ACKNOWLEDGMENTS}

This work was supported by The Southern \& Eastern Norway Regional Health Authority (A.V. grant numbers 2010007, 2017069) and The Research Council of Norway (grant number 223273). The authors wish to thank Linn Sofie Sæther for her help in creating the figures and extend their gratitude to the participants for contributing their time to research and to research personnel for conducting the clinical and neuropsychological assessments.

\section{CONFLICT OF INTEREST}

The authors have nothing to disclose.

\section{SUPPLEMENTARY MATERIAL}

To view supplementary material for this article, please visit https://doi.org/10.1017/S1355617720000442

\section{REFERENCES}

Arts, B., Jabben, N., Krabbendam, L., \& van Os, J. (2008). Meta-analyses of cognitive functioning in euthymic bipolar patients and their first-degree relatives. Psychological Medicine, 38, 771-785.

Baune, B.T. \& Malhi, G.S. (2015). A review of the impact of cognitive dysfunction on social, occupational, an general functional outcomes in bipolar disorder. Bipolar Disorders, 17(suppl.2), 41-55.

Birchwood, M., Smith, J., Cochrane, R., Wetton, S., \& Copestake, S. (1994). The Social Functioning Scale: the development and validation of a new measure of social adjustment for the use in family intervention programs with schizophrenic patients. British Journal of Psychiatry, 157, 853-859.

Bora, E., Yucel, M., \& Pantelis, C. (2009). Cognitive endophenotypes of bipolar disorder: a meta-analysis of neuropsychological deficits in euthymic patients and their first-degree relatives. Journal of Affective Disorders, 113, 1-20.

Bora, E. (2015). Developmental trajectory of cognitive impairment in bipolar disorder: comparison with schizophrenia. European Neuropsychopharmacology, 25, 158-168.

Bortolato, B., Miskowiak, K.W., Köhler, C.A., Vieta, E., Carvalho, A.F. (2015). Cognitive dysfunction in bipolar disorder and schizophrenia: a systematic review of meta-analyses. Neuropsychiatric Disease and Treatment, 11, 3111-3125.

Bowie, C.R., Twamley, E.W., Anderson, H., Halpern, B., Patterson, T.L, \& Harvey, P.D. (2007). Self-assessment of functional status in schizophrenia. Journal of Psychiatric Research, 41, 1012-1018.

Burdick, K.E., Russo, M., Frangou, S., Mahon, K., Braga, R.J., Shanahan, M., \& Malhotra, A.K. (2014). Empirical evidence for discrete neurocognitive subgroups in bipolar disorder: clinical implications. Psychological Medicine, 44, 3083-3096.

Calinski, T. \& Harabasz, J. (1974). A dendrite method for cluster analysis. Communications in Statistics, 3, 1-27.

Carruthers, S.P, Van Rheenen, T.E., Gurvich, C., Sumner, P.J., \& Rossell, S.L. (2019a). Characterising the structure of cognitive heterogeneity in schizophrenia spectrum disorders: a systematic review and narrative synthesis. Neuroscience and Biobehavioral Reviews, 107, 252-278.

Carruthers, S.P., Gurvich, C.T., Meyer, D., Australian Research Bank, Bousman, C., Everall, I.P., ... Rossell, S.L. (2019b). Exploring heterogeneity on the Wisconsin Card Sorting Test in schizophrenia spectrum disorders: a cluster analytic investigation. Journal of the International Neuropsychological Society, 25, 750-760.

Delis, D., Kaplan, E., \& Kramer, J.H. (2005). Delis-Kaplan Executive Function System: Examiner's Manual. Stockholm: Pearson Assessment.

Delis, D., Kramer, J.H., Kaplan, E., \& Ober, B.A. (2004). California Verbal Learning Test: CVLT-II. Stockholm: Pearson Assessment.

Demmo, C., Lagerberg, T.V., Kvitland, L.R., Aminoff, S.R., Hellvin, T., Simonsen, C., ... Ueland, T. (2018). Neurocognitive functioning, clinical course and functional outcome in first-treatment bipolar I disorder patients with and without clinical relapse: a 1-year follow-up study. Bipolar Disorders, 20, 228-237.

Dickinson, D., Ramsey, M.E., \& Gold, J.M. (2007). Overlooking the obvious: a meta-analytic comparison of digit symbol coding tasks and other cognitive measures in schizophrenia. Archives of General Psychiatry, 64, 533-542.

First, M., Spitzer, R., Gibbon, M., \& Williams, J. (1995). Structured clinical interview for DSM-IV Axis I disorders, patient edition (SCID-P), version 2. New York: New York State Psychiatric Institute, Biometrics Research.

Green, M.F., Kern, R.S., \& Heaton, R.K. (2004). Longitudinal studies of cognition and functional outcome in schizophrenia: 
implications for MATRICS. Schizophrenia Research, 72, 41-51.

Green, M.F., Horan, W.P., \& Lee, J. (2019). Nonsocial and social cognition in schizophrenia: current evidence and future directions. World Psychiatry, 18, 146-161.

Hellvin, T., Sundet, K., Vaskinn, A., Simonsen, C., Ueland, T., Andreassen, O.A., \& Melle, I. (2010). Validation of the Norwegian version of the Social Functioning Scale for schizophrenia and bipolar disorder. Scandinavian Journal of Psychology, 51, 525-533.

Jensen, J.H., Knorr, U., Vinberg, M., Kessing, L.V., \& Miskowiak, K.W. (2016). Discrete neurocognitive subgroups in fully or partially remitted bipolar disorder: associations with functional abilities. Journal of Affective Disorders, 205, 378-386.

Kahn, R.S. \& Keefe, R.S. (2013). Schizophrenia is a cognitive illness: time for a change in focus. JAMA Psychiatry, 70, 1107-1112.

Kay, S.R., Fiszbein, A., \& Opler, L.A. (1987). The positive and negative syndrome scale (PANSS) for schizophrenia. Schizophrenia Bulletin, 13, 261-276.

Keefe, R.S., Eesley, C.E., \& Poe, M.P. (2005). Defining a cognitive function decrement in schizophrenia. Biological Psychiatry, 57, 688-391.

Kendler, K.S., Ohlsson, H., Sundquist, J., \& Sundquist, K. (2015). IQ and schizophrenia in a Swedish national sample: their causal relationship and the interaction of IQ with genetic risk. American Journal of Psychiatry, 172, 259-265.

Khandaker, G.M., Barnett, J.H., White, I.R., \& Jones, P.B. (2011). A quantitative meta-analysis of population-based studies of premorbid intelligence and schizophrenia. Schizophrenia Research, 132, 220-227.

Kløve, H. (1963). Clinical neuropsychology. Medical Clinics of North America, 47, 1647-1658.

Koenen, K.C., Moffitt, T.E., Roberts, A.L., Martin, L.T., Kubzansky, L., Harrington, H., \& Caspi, A. (2009). Childhood IQ and adult mental disorders: a test of the cognitive reserve hypothesis. American Journal of Psychiatry, 166, 50-57.

Lewandowski, K.E., Sperry, S.H., Cohen, B.M., Öngur, D. (2014). Cognitive variability in psychotic disorders: a cross-diagnostic cluster analysis. Psychological Medicine, 44, 3239-3248.

Lewandowski, K.E., Baker, J.T., McCarthy, J.M., Norris, L.A., \& Öngur, D. (2018). Reproducibility of cognitive profiles using cluster analysis. Journal of the International Neuropsychological Society, 24, 382-390.

MacCabe, J.H., Lambe, M.P, Cnattingius, S., Sham, P.C, David, A.S., Reichenberg, A., ... Hultman, C.E. (2010). Excellent school performance at age 16 and risk of adult bipolar disorder. British Journal of Psychiatry, 196, 109-115.

Menkes, M.W., Armstrong, K., Balckford, J.U., Heckers, S., \& Woodward, N.D. (2019). Neuropsychological functioning in early and chronic stages of schizophrenia and psychotic bipolar disorder. Schizophrenia Research, 206, 413-419.

Meyers, J.E. \& Meyers, K.R. (1995). Rey Complex Figure Test and Recognition Trial. Odessa, FL: Psychological Assessment Resources.

Milligan, G.W. \& Cooper, M.C. (1985). An examination of procedures for determining the number of clusters in a data set. Psykometrika, 50, 159-179.

Parellada, M., Gomez-Vallejo, S., Burdeus, M., \& Arango, C. (2017). Developmental differences between schizophrenia and bipolar disorder. Schizophrenia Bulletin, 43, 1176-1189.
Pedersen, G., Hagtvedt, K.A., \& Karterud, S. (2007). Generalizability studies of the global assessment of functioning-split version. Comprehensive Psychiatry, 48, 88-94.

Rush, A.J., Guillon, C.M., Basco, M.R., Jarrett, R.B., \& Trivedi, M.H. (1996). The Inventory of Depressive Symptomatology (IDS): psychometric properties. Psychological Medicine, 26, 477-486.

Sabbag, S., Twamley, E.W., Vella, L., Heaton, R.K., Patterson, T.L., \& Harvey, P.D. (2012). Predictors of the accuracy of self assessment of everyday functioning in people with schizophrenia. Schizophrenia Research, 137, 190-195.

Schaefer, J, Giangrande, E., Weinberger, D.R., \& Dickinson, D. (2013). The global cognitive impairment in schizophrenia: consistent over decades and around the world. Schizophrenia Research, 150, 42-50.

Sheffield, J.M., Karcher, N.R., \& Barch, D.M. (2018). Cognitive deficits in psychotic disorders: a lifespan perspective. Neuropsychology Review, 28, 509-533.

Siqveland, J., Dalsbø, T.K., Harboe, I., \& Leiknes, K.A. (2014). Psychometric Evaluation of the Norwegian Version of the Wechsler Abbreviated Scale of Intelligence. Oslo, Norway: Norwegian Knowledge Center for the Health Services.

Smith, D.J., Amderson, J., Zammit, S., Meyer, T.D., Pell, J.P., \& Mackay, D. (2015). Childhood IQ and risk of bipolar disorder in adulthood: Prospective birth cohort study. The British Journal of Psychiatry Open, 1, 74-80.

Sundet, K. \& Vaskinn, A. (2008). Estimating premorbid IQ (in Norwegian with English abstract). Journal of the Norwegian Psychological Association, 45, 1108-1115.

Tiihonen, J., Haukka, J., Henriksson, M., Cannon, M., Kieseppä, T., ... Lönnqvist, J. (2005). Premorbid intellectual functioning in bipolar disorder and schizophrenia: results from a cohort study of male conscripts. American Journal of Psychiatry, 162, 1904-1910.

Tohen, M., Frank, E., Bowden, C.L., Colom, F., Ghaemi, S.N., Yatham, L.N., ... Berk, M. (2009). The International Society for Bipolar Disorders (ISBD) Task Force report on the nomenclature of course and outcome in bipolar disorders. Bipolar Disorders, 11, 453-473.

Torres, I.J., Qian, H., Basivireddy, J., Chakrabarty, T., Wong, H., Lam, R.W., \& Yatham, L.N. (2020). Three-year longitudinal cognitive function in patients recently diagnosed with bipolar disorder. Acta Psychiatrica Scandinavica, 141, 98-109.

Trotta, A., Murray, R.M, \& MacCabe, J.H. (2015). Do premorbid and post-onset cognitive functioning differ between schizophrenia and bipolar disorder? A systematic review and meta-analysis. Psychological Medicine, 45, 381-394.

Van Rheenen, T.E., Lewandowski, K.E., Tan, E.J., Ospina, L.H., Ongur, D., Neill, E., .. Burdick, K.E. (2017). Characterizing cognitive heterogeneity on the schizophrenia-bipolar disorder spectrum. Psychological Medicine, 47, 1848-1864.

Van Rheenen, T.E., Cropley, V., Zalesky, A., Bousman, C., Wells, R., Bruggemann, J., ... Pantelis, C. (2018). Widespread volumetric reductions in schizophrenia and schizoaffective patients displaying compromised cognitive abilities. Schizophrenia Bulletin, 44, 560-574.

Van Rheenen, T.E., Lewandowski, K.E., Bauer, I.E., Kapczinski, F., Miskowiak, K., Burdick, K.E., \& Balanzá-Martìnez, V. (2020). Current understandings of the trajectory end emerging correlates of cognitive impairment in bipolar disorder: an overview of evidence. Bipolar Disorders, 22, 13-27.

Vaskinn, A., Ueland, T., Melle, I., Agartz, I., Andreassen, O.A., \& Sundet, K. (2014). Neurocognitive decrements are present 
in intellectually superior schizophrenia. Frontiers Psychiatry, 5,45 .

Vendramin, L., Campello, R.J.G.B, \& Hruschka, E.R. (2010). Relative clustering validity criteria: a comparative review. Statistical Analysis and Datamining, 3, 209-235.

Wechsler, D., Wycherly, R.J., \& Benjamin, L. (1998). Wechsler Memory Scale: WMS-III. San Antonio, TX: The Psychological Corporation.

Wechsler, D. (2003). Wechsler Adult Intelligence Scale: WAIS-III. Stockholm: Pearson Assessment.

Wechsler, D. (2007). Wechsler Abbreviated Scale of Intelligence. Norwegian Manual Supplement. Stockholm: Pearson Assessment. Weickert, T.W., Goldberg, T.E., Gold, J.M., Bigelow, L.B, Egan, M.F., \& Weinberger, D.R. (2000). Cognitive impairments in patients with schizophrenia displaying preserved and compromised intellect. Archives of General Psychiatry, 57, 907-913.
Wells, R., Swaminathan, V., Sundram, S., Weinberg, D., Bruggemann, J., Jacomb, I., ... Weickert, T.W. (2015). The impact of premorbid and current intellect in schizophrenia: cognitive, symptom, and functional outcomes. NPJ Schizophrenia, 1,15043 .

Weinberg, D., Lenroot, R., Jacomb, I., Allen, K., Bruggemann, J., Wells, R., ... Weickert, T.W. (2016). Cogntive subtypes of schizophrenia characterized by differential brain volumetric reductions and cognitive decline. JAMA Psychiatry, 73, $1251-1259$.

Wykes, T., Huddy, V., Cellard, C., McGurk, S.R., \& Czobor, P. (2011). A meta-analysis of cognitive remediation for schizophrenia: methodology and effect sizes. American Journal of Psychiatry, 168, 472-485.

Young, R.C., Biggs, J.T., Ziegler, V.E., \& Meyer, D.A. (1978). A rating scale for mania: reliability, validity and sensitivity. British Journal of Psychiatry, 133, 429-435. 